\title{
Experimental Study on the Effect of Water Injection in an Internal Combustion Engine
}

\author{
A.A. Iyer, I.P. Rane, K.S. Upasani, Y.P. Bhosale S.H. Gawande \\ (Department of Mechanical Engineering, M.E.S. College of Engineering, S.P. Pune University, India)
}

\begin{abstract}
The Emissions from combustion of fuels such as petrol and diesel in I.C. engines and the particulate matter released have been major part of the air pollution sources, especially in urban areas. It has always been the cause of severe public health issues for so long. A lot of research has been carried out in the field of reduction of these pollutants since diesel engines came into prime use. The Main emissions from a diesel engine are Oxides of Nitrogen (NOx), Carbon Monoxide (CO), Oxides of Sulphur (SOx) and particulate matter (PM). The use of an emulsion of diesel in water as a fuel has been a recent subject of study in this sector. Without compromising on the engine's performance, Water/diesel (W/D) emulsified formulations have evidently reduced the emissions of $\mathrm{CO}, \mathrm{SOx}, \mathrm{NOx}$ and particulate matter (PM) significantly. The depleting amount of Natural resources like natural gas, petroleum oil is evident by the ever escalating prices of crude oil, and is increased by transportation losses viz. leakages and oil spills. The fuel efficiency of the vehicle is the key factor while purchasing new vehicle
\end{abstract}

Keywords: Emissions, Pollution, Catalytic Converter, Fuel Consumption, Internal Combustion Engines.

\section{Introduction}

With the increasing prices of Oil and the ever reducing supplies of Petroleum, it is necessary to look towards new solutions for transport purposes. Electric vehicles will undoubtedly be the solution. Till then, there is need for optimum use of current technology as well as resources. Global warming is another problem which is caused largely due to the harmful emissions from the exhausts of automobiles. The pollutants exhausted from the I.C. engines have an effect on the atmosphere causing issues such as smog, acid rain, global warming, respiratory hazards etc. Non-stoichiometric combustion, separation of nitrogen and impurities in the air fuel mixture cause these emissions The higher amounts of emissions include unburnt Hydrocarbons (HC), Nitrogen Oxides (NOx), Oxides of Sulphur, oxides of Carbon, and soot. These pollutants can be treated in many ways. Two of the eminent ways are - treatment in-cylinder and post treatment or treatment out-cylinder. Treatment inside the cylinder will be focused on throughout the course of the project. This will be achieved by a process called Water Injection

\section{Factors Affecting Engine Performance}

2.1 Intake Air Temperature

- Intake Temperature is the temperature of the air charge inducted into the intake manifold.

- Higher intake temperature consists of air which is less dense.

- Lower temperature air is denser - containing more oxygen for combustion.

- Intake Temp for Naturally Aspirated Engine: $25^{\circ}-30^{\circ}$ Intake Temp for Forced Induction Engine: $55^{\circ}-60^{\circ}$ (After Intercooling)

\subsection{Air-Fuel Ratio}

- Air Fuel Ratio is the instantaneous ratio of the amount of charge air to the amount of fuel to be ignited.

- It is classified Into 3 distinct zones - lean, stoichiometric (Idling) \& power.

- Changing the air-fuel ratio will directly have an effect on the amount of fuel an engine requires to produce the same work.

\subsection{Engine Speed}

- Engine speed is the speed at which the crankshaft of the engine rotates.

- Engine speed directly affects fuel efficiency \& emissions.

- High engine speed reduces the time for the combustion of fuel, and leads to high temperature.

- Injecting water into the intake manifold reduces the charge temperature.

- Water Injection is currently used in higher speed engines mainly for power increase.

2.4 Working Temperature 
- The overall operating temperature of the engine is the working temperature of the engine.

- As the speed increases, the working temperature increases.

- Higher working temperature leads to higher emissions \& incomplete combustion.

- It also causes formation of "hot-spots" which leads to knocking of engine.

- The operating temperature of an IC Engine is around: $100^{\circ}-120^{\circ}$

\subsection{Incomplete Combustion \& Detonation}

- Higher working temperatures \& high engine speeds leads to incomplete combustion of the charge.

- Also, knocking phenomenon is observed due to formation of hot-spots inside the combustion chamber.

- By maintaining a lower temperature, hotspot formation can be avoided, thereby preventing knocking phenomenon.

- Higher engine speeds can be avoided as the engine can produce the same work \& operate more efficiently at a lower speed.

\subsection{Heat Losses}

- The overall efficiency of an IC Engine is in the range of $35-45 \%$

- The remaining energy is lost in the form of heat losses.

- Heat is lost to the cylinder walls, exhaust manifold, piping, etc.

- The water entering the combustion chamber will interact the walls of the engine and absorb the heat energy from it.

\section{Literature Review}

Extensive research work has been carried out in the field of water injection in an internal combustion engine. The current project is a cumulative work of these research papers in combination to reduce the overall emissions Busuttil et al.[1] experimentally investigated the optimum quantity of water to be injected for a particular engine. The experimentation was done using a combination of injectors and a specially designed circuit Breda et al.[2] investigated using CFD analysis the solutions to increase the knock resistance. Methanol, water or a combination of both is added to the intake manifold to maintain the knock resistance. 87Ma et al.[3] observed that introducing Intake Manifold Water Injection has positive effects on mainly three parameters namely- Chemical Effect, Dilution Effect and Thermal Effect Boretti [4] found that Injection of water upstream proved effective in reducing the temperature of gases and at the entry of engine which resulted in increasing power densities and better fuel efficiencies for same temperature of turbocharger Daggart et al.[5] along with Rolls Royce Corporation and Boeing Company has been working with NASA to study the effects of water injection in an aircraft turbine engine. Various types of water injection techniques were implemented and investigated Roumeliotis et al.[6] investigated the results of water injection in an internal combustion engine in old internal combustion engines to improve their overall performance Totala [7] found that introducing $5050 \%$ mixture of methanol and water reduces the $\mathrm{CO}$ and $\mathrm{HC}$ emissions by $8.8 \%$ and $22.8 \%$ respectively Bernie et al.[9] performed 3D CFD analysis to analyze the overall knock resistance in an IC engine and analyze the overall water/fuel mixture required.

\subsection{Emulsion}

\section{Classification}

The Emulsion system consists of two immiscible liquids, one being finely dispersed into the other. For all water/diesel duel emulsions, fine droplets of water are dispersed continuously in the diesel fuel. Such type of emulsion method is called as "water-in-fuel". If the opposite configuration i.e. if fuel mist is mixed in continuous water phase, there would be high probability of water contacting the liner surface inside the cylinder and other metal parts which may cause corrosion and leading to engine problems. Use of water- fuel emulsion for running engine makes it viable to cut the $\mathrm{NO}_{\mathrm{x}}$ up to $50 \%$, where the quantity of water required for each percentage reduction in $\mathrm{NO}_{\mathrm{x}}$ is about one percent. The delivery capacity of the system limits the water emulsion application. Without making any engine modifications (e.g. using substitute fuel in current engines), the amount of $\mathrm{NO}_{\mathrm{x}}$ reduction and the maximum amount of water emulsified is limited to around 10-20\%. Even after achieving the calculated conditions, the engine may not produce its rated power and run at a derated condition

\subsection{In-Cylinder Injection}

In-cylinder water injection relies on a injection system which is fully independent and preferably controlled electronically. This process allows large amounts of water to be injected without having to derate the engine. The 


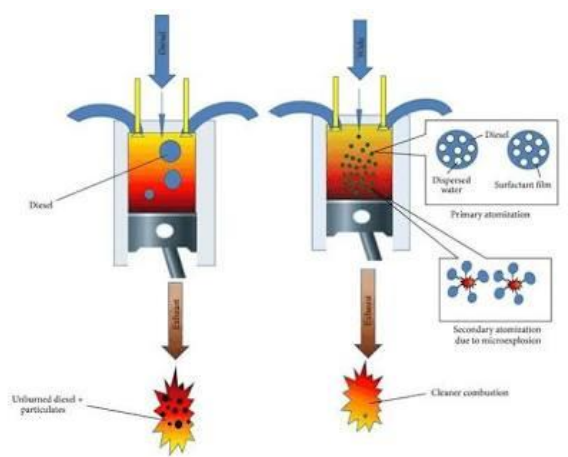

Fig. 1: Emulsion type of Water Injection

freedom to shut the water injection off or switch on, as required, without having an effect on engine reliability, is granted. Direct water injection requires careful optimization with respect to the timing of injection, water flow rate, emissions etc. parameters. $\mathrm{NO}_{\mathrm{x}}$ reductions as much as emulsion systems can be achieved due to the flexibility of the optimizing parameters, even though the water is not introduced directly into the area of the diesel flame as the integral spray part. Though the PM emissions, if any, cannot match the emulsion systems. The water injection systems for different engines require complex development works, thus making this approach more suitable for OEM applications instead of retrofit applications.

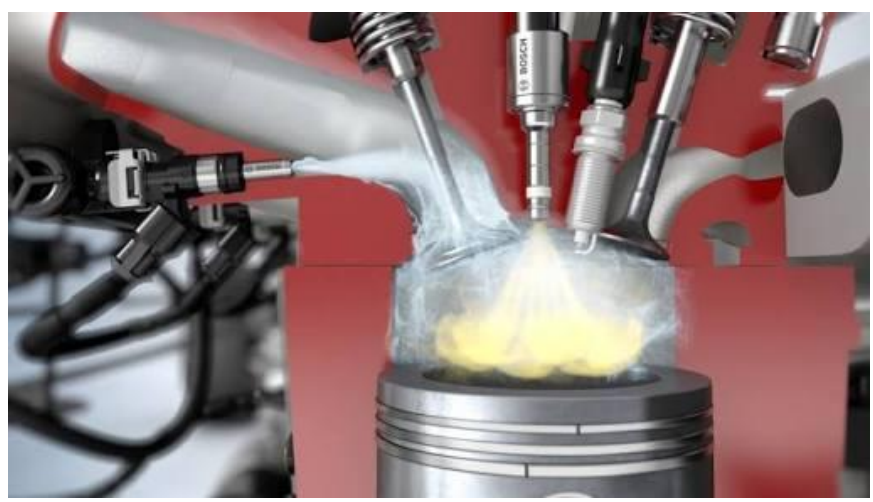

Fig. 2: In-Cylinder Type of Water Injection

\subsection{Fumigation}

The process of introduction of water mist into the air intake is called as Fumigation and is the simplest method of water addition. In this method the control over injection parameters like spatial co-ordinates and timing is limited. Due to this, the $\mathrm{NO}_{\mathrm{x}}$ reductions tend to be lower as compared to in-cylinder injection and emulsion method. The $\mathrm{NO}_{\mathrm{x}}$ reduction in fumigation is generally around $10 \%$ per $20 \%$ water added to the fuel. Incomplete evaporation of water in fumigation may cause the water to impinge on the walls of the cylinder causing the lube oil film to damage and cause engine damage. Thus fumigation of water vapor rather than liquid is considered safer. The generation of the required water vapor can be done using the waste engine heat e.g. heat from exhaust gases, compressed air charge etc. Other option is to use steam, which is applicable for certain stationary operations

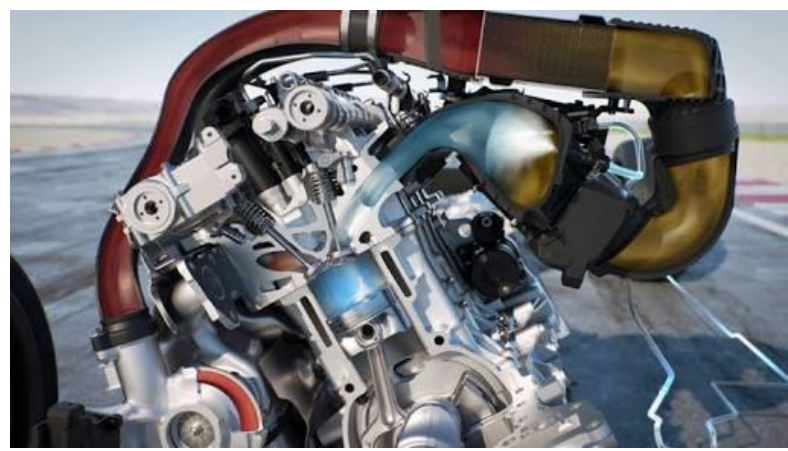

Fig. 3: Fumigation Type of Water Injection 


\section{Circuit Diagram}

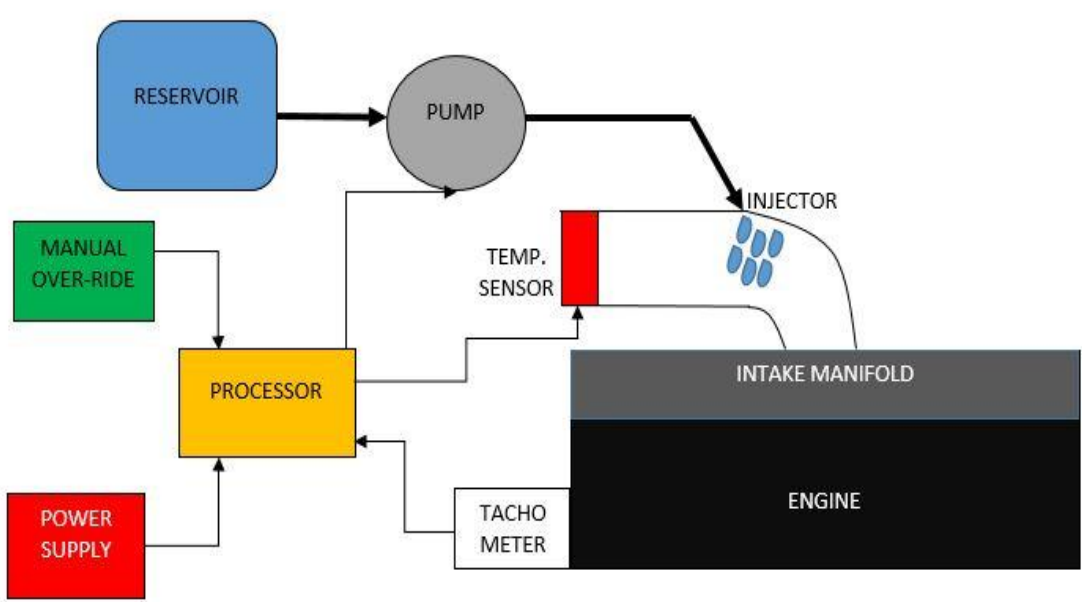

Fig. 4: Circuit Diagram of Water Injection

The processor reads and analyses the temperature input from the temperature sensor and the Tachometer. When the set threshold inputs are met, the processor activates the water pump and the injector and deactivates them when the ideal input values are achieved. A manual override switch is also given for safety reasons.

Displacement: $2523 \mathrm{cc}$

\section{Analytical Analysis}

Density of air: $1.225 \mathrm{~kg} / \mathrm{m}^{3}$

Volumetric Efficiency: $>100 \%$

Manifold Air Pressure: 2 atm

Engine Speed: $3200 \mathrm{rpm}$

No. of Cycles: 1600

Stoichiometric Air/Fuel Ratio: 15:1

Compression Ratio: 18.1:1

Air Consumed $=0.0025 * 1600 * 100 \% * 2 * 1.225$

Hence, Air Consumed $=9.8 \mathrm{~kg} / \mathrm{min}$

Amount of Fuel Consumed $=\frac{9.8}{15}=0.6533 \mathrm{~kg} / \mathrm{min}$

$v=v_{f}+x \cdot v_{g}$

$v_{f}=$ specific volume (saturated water)

$v_{g}=$ specific volume (saturated steam)

$h_{f}=$ specific enthalpy

$h_{f g}=$ latent heat of evaporation

$x_{1}=\frac{v-v_{f}}{v_{g}}$

$x_{1}=\frac{0.0016-0.00102}{7.6672}$ 
$x_{1}=7.56 \times 10^{-5}$

- Calculation of Internal Energy

$u_{1}=u_{f 1}+x_{1} \cdot u_{g}$

At $t=60^{\circ}$,

$u_{f 1}=251.16 \mathrm{KJ} / \mathrm{Kg}$

$u_{g}=2455.9 \mathrm{KJ} / \mathrm{Kg}$

$u_{1}=251.435 \mathrm{KJ} / \mathrm{Kg}$

Assuming Final Condition,

Reduction of Temp by $30^{\circ}$

$T_{\text {final }}=30^{\circ}$

$v_{f}=0.001 \mathrm{~m}^{3} / \mathrm{Kg}$

$v_{g}=32.878 \mathrm{~m}^{3} / \mathrm{Kg}$

$x_{2}^{\prime}=\frac{v-v_{f 1}}{v_{g}}$

$x_{2}{ }^{\prime}=1.824 \times 10^{-5}$

$u_{2}{ }^{\prime}=u_{f}{ }^{\prime}+x_{2}{ }^{\prime} \cdot u_{g}{ }^{\prime}$

$u_{2}^{\prime}=125.77 \mathrm{KJ} / \mathrm{Kg}$

By theoretical calculations,

$u_{2}=u_{1}+\frac{Q \Delta t}{m}$

$Q=m \cdot C_{p} \cdot \Delta t$

Where $\Delta t=30^{\circ}$

$C_{p_{\text {air }}}=1005 \mathrm{~J} / \mathrm{Kg}$

$\dot{m}=\frac{9.8}{60} K g / \mathrm{sec}$

$Q=4.9245 K W$

$u_{2}=251.345+\frac{4.9245 \times 30 \times 0.5}{1.6}$

$u_{2}=297.512 \mathrm{KJ} / \mathrm{Kg}$

$x_{2}^{\prime \prime}=1.384 \times 10^{-4}$

$u_{2}^{\prime \prime}=u_{f}^{\prime \prime}+x_{2}^{\prime \prime} \cdot u_{g}^{\prime \prime}$

$u_{2}^{\prime \prime}=104.88+1.384 \times 10^{-4} \times 2409.1$

$u_{2}^{\prime \prime}=104.86 K J / K g$

By Interpolation,

$X=\frac{x_{2}{ }^{\prime \prime}-x_{2}^{\prime}}{u_{2}{ }^{\prime \prime}-u_{2}^{\prime}} \cdot\left(u_{2}-u_{2}^{\prime}\right)$

$X=10^{-4} \times\left(\frac{1.384-1.824}{104.86-125.77}\right) \cdot(297.512-125.7)$ 
$\Delta m v=m\left(x_{1}-x_{2}\right)$

$\Delta m v=3.395 \times 10^{-5} l$

The calculations indicate the amount of water to be injected per unit time

VII. Results And Discussions

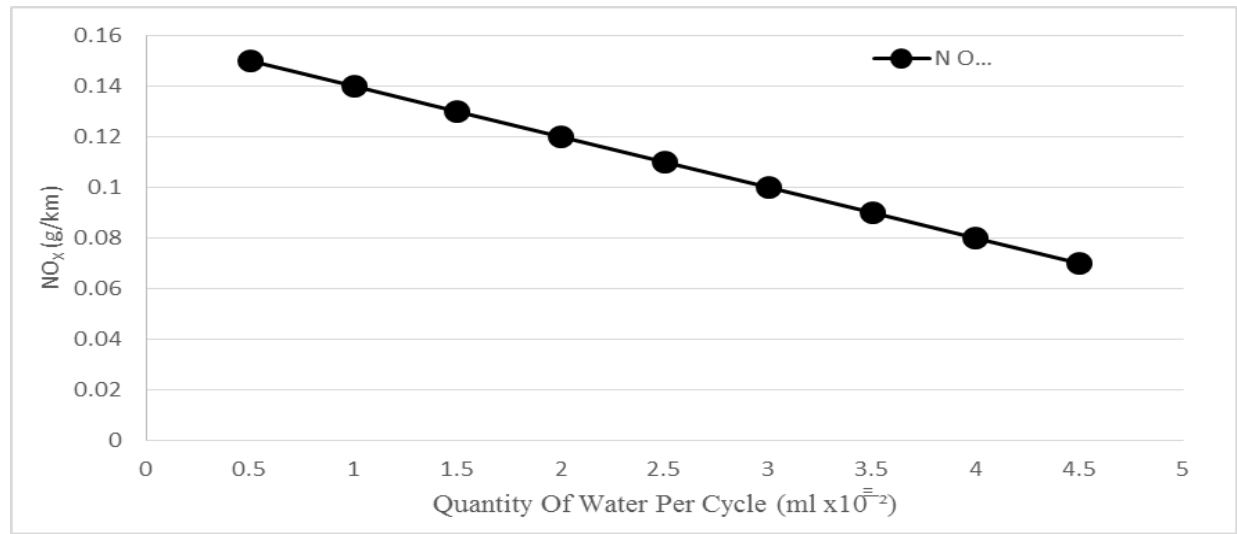

Fig. 5: $\mathrm{NO}_{\mathrm{x}} \mathrm{v} / \mathrm{s}$ Quantity of water

Table no.1

\begin{tabular}{|c|c|c|c|}
\hline Sr.No & Quantity of water $(\mathrm{ml}) \times 10^{-2}$ & NOx $(\mathrm{g} / \mathrm{km})$ & Temperature $\left({ }^{\circ} \mathrm{c}\right)$ \\
\hline 1 & 0 & 0.15 & 60 \\
\hline 2 & 0.5 & 0.14 & 55.7 \\
\hline 3 & 1 & 0.13 & 51.3 \\
\hline 4 & 1.5 & 0.12 & 47 \\
\hline 5 & 2 & 0.11 & 42.3 \\
\hline 6 & 2.5 & 0.1 & 37 \\
\hline 7 & 3 & 0.09 & 32.5 \\
\hline 8 & 3.1 & 0.08 & 31.4 \\
\hline 9 & 3.2 & 0.07 & 31 \\
\hline 10 & 3.3 & 0.06 & 30.6 \\
\hline 11 & 3.4 & 0.05 & 29.9 \\
\hline 12 & 3.5 & 0.04 & 29.7 \\
\hline 13 & 4 & 0.03 & 29.5 \\
\hline
\end{tabular}

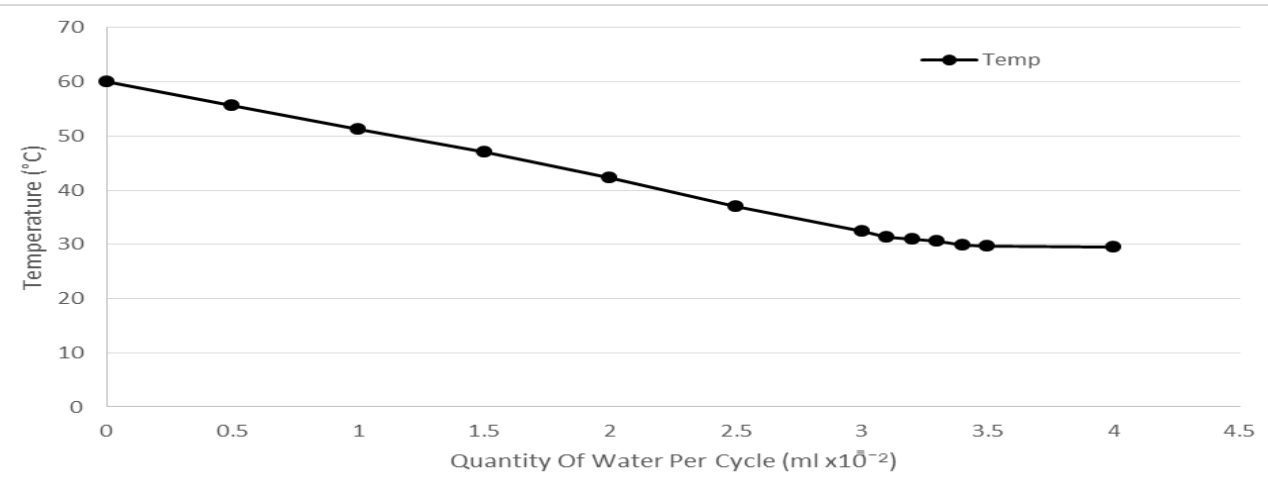

Fig. 6: Temperature v/s Quantity of water per cycle (ml)

From Table no. 1 and Fig.5 and Fig. 6, the following result was established.

With increasing amount of water in the intake manifold, the subsequent intake air temperature reduces up to the optimum water spray rate i.e. $0.039 \mathrm{ml} / \mathrm{min}$ as shown in Fig. 6. Beyond the optimum point, the slope of the graph reduces drastically. Also from Fig.5 it can be seen that a liner relationship can be drawn between the $\mathrm{NO}_{\mathrm{x}}$ emissions and the quantity of water injected. With increasing amount of water injected, the $\mathrm{NO}_{\mathrm{x}}$ emissions reduce linearly to approximately $9 \%$ of its original quantity. 


\section{Conclusion}

Thus, the preliminary conclusion is that $0.0363 \mathrm{ml}$ of water must be injected in the engine per cycle for complete vaporization. This value will help in selecting the pump and injectors of the appropriate specifications. This is the amount of water to be injected in order to cool the intake charge to $30^{\circ} \mathrm{C}$.

\section{References}

[1] D. Busuttil, M. Farrugia, Experimental Investigation on the Effect of Injecting Water to the Air Fuel Mixture in a Spark Injection Engine, Science Journal, Vol 3, 2015, 585- 590

[2] S. Breda, F. Berni, A. D'Adamo, F. Testa, E. Severi, and G. Cantore, Effects on knock intensity and specific fuel consumption of port water/methanol injection in a turbocharged GDI engine: Comparative analysis, Energy Procedia, vol. 82, 2015,96-102.

[3] X. Ma, F. Zhang, K. Han, Z. Zhu, and Y. Liu, Effects of intake manifold water injection on combustion and emissions of diesel engine, Energy Procedia, vol. 61, 2014,777-781.

[4] A. Boretti, Water injection in directly injected turbocharged spark ignition engines, Applied. Thermal Engineering., vol. 52, no. 1,2013, 62-68.

[5] D. L. Daggett, L. Fucke, B. C. Airplane, R. C. Hendricks, and D. J. H. Eames, Water Injection on Commercial Aircraft to Reduce Airport Nitrogen Oxides,2010, Nasa/Tm-2010-213179.

[6] I. Roumeliotis and K. Mathioudakis, Evaluation of water injection effect on compressor and engine performance and operability, Appl. Energy, vol. 87, 2010,no. 4, 1207-1216,

[7] N. B. Totala, Pratyush, A. Hussain, M. Tajkhan, Siddharth, Performance analysis of 4-stroke single cylinder SI engine and preheating gasoline and Injecting 50\% volume/volume water Methanol mixture in carburetor, Indian Journal of Applied Research, vol 3, issue 7,2013, 293-296

[8] R. Cameron, "Effects of On-board HHO and Water Injection in a Diesel Generator", A dissertation University of Southern Queensland Faculty of Engineering and Surveying, 2012.

[9] F. Berni, S. Breda, M. Lugli, and G. Cantore, A numerical investigation on the potentials of water injection to increase knock resistance and reduce fuel consumption in highly downsized GDI engines, Energy Procedia, vol. 81, $2015,826-835$.

[10] F. Bozza, V. De Bellis, and L. Teodosio, Potentials of cooled EGR and water injection for knock resistance and fuel consumption improvements of gasoline engines, Appl. Energy, vol. 169, 2016, 112-125. 